University of Wollongong

Research Online

Faculty of Business - Papers (Archive)

Faculty of Business and Law

$1-1-2015$

Guest editorial: information technology-enabled supply chain management

Samuel Fosso Wamba

NEOMA Business School,, samuel.fosso.wamba@neoma-bs.fr

Shahriar Akter

University of Wollongong, sakter@uow.edu.au

Tim Coltman

University of Wollongong, tcoltman@uow.edu.au

Eric W. T Ngai

Curtin University, The Hong Kong Polytechnic University

Follow this and additional works at: https://ro.uow.edu.au/buspapers

Part of the Business Commons

Research Online is the open access institutional repository for the University of Wollongong. For further information contact the UOW Library: research-pubs@uow.edu.au 


\title{
Guest editorial: information technology-enabled supply chain management
}

\begin{abstract}
It is widely accepted that advances in information technology (IT) will generate new opportunities when suppliers, business partners and customers work together to co-create and co-produce value. However, results from prior studies show that the mere possession of IT is unlikely to generate business value. Rather, IT creates value when information - frequently produced by IT infrastructure - is used to support complementary organizational and human resources. Still, the hypothesis that greater investment in IT will generate business value requires caution. The focus of this special issue is to extend our understanding of how firms in a supply chain create and capture business value with IT. Also, a review is provided of the IT business value literature in the journal Production Planning \& Control: The Management of Operations. This literature is grouped into three types of business value: transactional, strategic, and transformational. The review justifies the importance of this special issue by highlighting the dearth of research on the topic in this journal. Lastly, future research directions are provided and this introduction concludes with a guide to the papers in this special issue.
\end{abstract}

\section{Keywords}

information, editorial, guest, management, chain, supply, enabled, technology

Disciplines

Business

\section{Publication Details}

Fosso Wamba, S., Akter, S., Coltman, T. \& Ngai, E. W. T. (2015). Guest editorial: information technologyenabled supply chain management. Production Planning and Control, 26 (12), 933-944. 


\title{
Guest Editorial: Information Technology-enabled Supply Chain Management
}

\author{
Samuel Fosso Wamba, Shahriar Akter, Tim Coltman, Eric W. T. Ngai
}

Authors

\author{
Samuel Fosso Wamba*, \\ NEOMA Business School \\ 1 Rue du Maréchal Juin \\ BP 215 Mont Saint Aignan Cedex, 76825, France \\ Tel: +33- 02-32-82-57-00 \\ And \\ UNISA, Preller St, Pretoria, 0002, South Africa \\ Shahriar Akter \\ School of Management, Operations and Marketing \\ University of Wollongong \\ Northfields Ave, Wollongong NSW 2522, Australia \\ Tim Coltman \\ School of Management, Operations and Marketing \\ University of Wollongong \\ Northfields Ave, Wollongong NSW 2522, Australia \\ Phone: +61 2 4221-3912; email: tim_coltman@uow.edu.au
}

Eric W. T. Ngai

Hong Kong Polytechnic University

Hong Kong

Corresponding author: *Samuel Fosso Wamba,

NEOMA Business School

1 Rue du Maréchal Juin

BP 215 Mont Saint Aignan Cedex, 76825, France

Tel: +33- 02-32-82-57-00

Email: Samuel.fosso.wamba@neoma-bs.fr 


\section{Introduction to the Special Issue}

It is widely accepted that advances in information technology (IT) will generate new opportunities when suppliers, business partners and customers work together to co-create and co-produce value. Studies point to the advantages that accrue when supply chain members share information in real time (Frohlich \& Westbrook, 2002), describing how different companies in a supply chain, with different IT, can coordinate activities to create new value that would not have been possible on their own (Grover \& Kohli, 2012,p.226). Reported examples of value creation based on IT are found in the use by Motorola and national mobile retailers of collaborative planning forecasting and replenishment tools that are used to gain more in-depth supply chain visibility_ensuring that shelves are fully stocked and inventory levels for leftover parts are reduced (Cederlund, Kohli, Sherer, \& Yao, 2007). Seven (7)-Eleven Japan used 70,000 interconnected point-of-sale terminals in stores, and computers at headquarters and supplier sites to capture real-time information and to track inventory and weather patterns. This data provided greater supply chain transparency, enabling store owners to strategically stock and price items thus changing the nature of retailing in Japan (Nagayama \& Weill, 2004).

However, the hypothesis that greater investment in IT will generate business value requires caution. In a provocative Harvard Business Review article titled “IT Doesn’t Matter”, Nicholas Carr (2003) argued that it is a mistake to believe IT alone will create strategic value because the core functions of IT_-data storage, data processing, and data transport-are neither scarce nor unaffordable. Gaining an advantage over rivals is based on having or doing something that others cannot do: Palmer and Markus (2000) claim that IT has become so institutionalized in firms that it no longer serves to differentiate firm performance as it once did. This research implies that the mere possession of IT is unlikely to generate business value. Rather, IT creates value when 
information - frequently produced by IT infrastructure - is used to support complementary organizational and human resources (Coltman \& Devinney, 2013; Coltman, Devinney, \& Midgley, 2011).

The focus of this special issue is to extend our understanding of how firms in a supply chain create and capture business value with IT. Managing the inter- and intra-organizational information systems (IS) required to support supply chain management (SCM) is difficult. Contractual hazards arise when upstream and downstream partners make asset-specific investments under conditions of uncertainty (Williamson, 1985). Contracting with suppliers requires parties to agree on common protocols and standards that govern data exchange. Behavioral challenges arise when suppliers behave opportunistically (Jap \& Anderson, 2003) or fail to prioritize the work that is required to support supply chain innovation. Thus, collaboration between supply chain stakeholders to create and capture value from IT is a challenge. This special issue seeks to contribute to this discussion.

The remainder of this introduction is structured as follows. First, the concept of business value is discussed. Second, a review is provided of the IT business value literature in the journal Production Planning \& Control: The Management of Operations: this literature is grouped into three types of business value: transactional, strategic, and transformational. The review justifies the importance of this special issue by highlighting the dearth of research on the topic in this journal. Lastly, future research directions are provided and this introduction concludes with a guide to the papers in this special issue.

\section{Business Value: A Definition}

The term "business value" crops up frequently in the business literature. However, despite the practical requirement to demonstrate value from investments in expensive resources, such as IT, 
the business value construct is poorly understood. Lepak, Smith and Taylor (2007, p.180) conclude in their paper that there is "little consensus on what value creation is or on how it can be achieved". They argue that "value creation depends on the relative amount of value that is subjectively realized by a target user (or buyer) who is the focus of value creation" (p. 182). According to this definition, concepts of value, value creation, and value capture are context-dependent.

Given the contextual nature of value and the focus of this special issue, the natural question to ask is: what exactly is the meaning of IT-derived value in a supply chain context? Information technology (IT) is a resource and, while considerable attention has been given to the possession of resources that are rare, valuable, imperfectly immutable, and imperfectly substitutable (Barney, 1991), far less attention has been given to what makes these resources valuable in the first instance. Using the resource-based perspective to ground their study, Bowman and Ambrosini (2000) define a theory of value that distinguishes between value creation - the perceived-use value that is subjectively assessed by the customer - and value capture - the exchange value that is the price paid for the use value created. These two dimensions of value help to explain why idiosyncratic supply chain configurations can allow particular organizations to offer greater use value than their competitors, thereby enabling these same organizations to capture above-average profits.

In a supply chain, the use value created by one firm can be captured by another firm which is in a better market position or has a better strategy. This complicates matters because the most efficient operation cannot be judged according to the firm's own profit (Carson, Timothy, Grahame, \& George, 1999). Performance by any one firm in a supply chain affects the profits of all firms in the ecosystem, and institutional arrangements, which consist of contracting, 
ownership, and social elements, tie together the joint profits in a supply chain. Thus, any firm in a supply chain can "capture more, the same or less value than the one it helps create". Thus, the nature of value creation in a supply chain makes the business case for technology investment more difficult when, for example, an upstream supplier incurs the costs for radio frequency identification tags that will often provide most use value to firms downstream in the supply chain. Complementary investments, risk allocation, capability building, adoption, absorption, and incentives are well-known challenges for collaborating organizations (Grover \& Kohli, 2012).

The concept of value co-creation-by multiple stakeholders including competitors, suppliers, customers, and users - is a fundamental concept in all service domains such as SCM (Vargo \& Lusch, 2008). According to the service-dominant logic literature, value creation is grounded in a "commitment to collaborative processes with customers, partners, and employees; a logic that challenges management at all levels to be of service to all stakeholders; a perspective that recognizes the organization and its exchange partners are engaged in the co-creation of value through reciprocal service provision” (Lusch, Vargo, \& O’Brien, 2007 ,p.7).

Pitelis (2009) argues that there is a trade-off between value creation and value capture. To him, the ability of a firm to create value should depend on its ability to establish interactions between the key determinants of value creation, which include innovation, human resource capabilities, appropriate business strategy and infrastructure, and the availability of physical and financial capital. Thus, value is a multidimensional construct: for the purposes of this introduction, three dimensions of "business value" are investigated. These three dimensions — transactional, strategic, and transformational value — have previously been found to explain the differential effects of IT on business value at the firm level (Gregor, Martin, 
Fernandez, Stern, \& Vitale, 2006; Mirani \& Lederer, 1998). The next section presents a review of what is known about IT-based value creation and value capture in SCM based on published papers in Production Planning \& Control: The Management of Operations.

\section{Descriptive Summary of the Role of IT in the Production Planning \& Control Journal}

Before addressing what is not known about IT-based value, it is important to take stock of what is currently known. To achieve this, we reviewed all articles published in Production Planning \& Control between January 2009 and June 2014. The identified papers discussed a broad range of issues regarding the functional use of IT (e.g., from advanced manufacturing to mobile technologies); the level in the organization (e.g., firm, department, and strategic business unit); and the outcomes of IT investment and adoption (e.g., benefits of implementing and using IT in product designs, advanced technologies for manufacturing operations, and supply chain partners). To classify the papers, we used the three dimensions of IT business value proposed by Gregor et al. (2006): transactional, strategic, and transformational. A detailed description of the methodology used to support this review is provided in Appendix A.

\section{Insights from the literature review}

Our literature review identified 12 relevant articles. In terms of the distribution of articles according to the dimensions of IT business value, the highest number of articles identified relates to the "transactional" dimension of IT business value (40\%), followed by the "strategic" dimension with 33\%, and finally the "transformational" dimension of IT business value with $27 \%$ of published articles.

The distribution of articles based on sectors reveals that the vast majority of articles published on IT business value are from the service sector (42\%, or five articles). This probably 
highlights the importance of the service sector in the current digital economy. Two (2) articles were concerned with the public sector (17\%), followed by the manufacturing sector (one article, 8\%). Finally, one article (8\%) dealt with multiple industries. We were unable to identify the sector of three articles (25\%).

The distribution of articles based on the research approach used is presented in Appendix B. The results from the table clearly show that the most common approach employed in the reviewed papers was case studies (six articles, 50\%), followed by survey studies (three articles, 25\%), and a combination of both questionnaire and mathematical modelling (one article, 8\%). Only one article (8\%) used experimental design as the primary research method, while another article "Advanced planning and scheduling technology" (Steger-Jensen et al. 2011) used mathematical modelling (8\%). A summary of key findings is also presented in Table 1 in Appendix B. We next discuss each dimension of business value according to Gregor et al.'s (2006) classification framework.

\section{Discussion on Business Value of IT for Selected Articles}

\section{Transactional Business Value}

Transactional business value refers to the benefits added to firms as a result of IT use through enhancing operation management, improving efficiency, and cutting costs for firms (Mirani \& Lederer, 1998). The transactional nature of value creation is illustrated in the study by Oztekin et al. (2013) where they applied Kansei engineering. This approach, encompassing customers' feelings into the product design, was conducted on a sample of Turkish firms. Results revealed that mobile devices were used in the product design stages to meet customer expectations and increase sales. Others have looked at the alignment of IT with business strategy. For example, Santa et al. (2013) show that alignment between technological innovation (service 
quality, information quality, and system quality) and operational effectiveness (cost, quality, reliability, flexibility, and speed) increases operational efficiency of service firms in Australia. Similarly, in their study in the Netherlands, Plugge and Bouwman (2012) explored the fit between IT outsourcing capabilities and organizational structure and the impact that this had on sustainable IT outsourcing performance from the suppliers' perspective. The findings of the study revealed that suppliers who emphasized fit were more capable of monitoring when they had achieved a sustainable performance. Their study provides further evidence that the offshore supplier and the global supplier can both achieve fit by aligning sourcing capabilities and organizational structures. In this case, both suppliers were able to improve performance.

Transactional business value from IT arises in both private and public sectors. Maguire et al. (2012) used two case studies in Greece to show that information and communications technology (ICT) provides many benefits for the public sector, illustrating how the service productivity of the public sector is improved with the implementation of ICT. These benefits include enabling better communication between departments in the government sector; facilitating electronic data exchange; ensuring timely and updated information for the introduction of new laws; and reducing time for file processing. Consequently, introducing technology-based government services, interactive citizen services, and improved data management services (incorporating accuracy, integrity, privacy, and data warehousing) was possible.

Studies have explored IT business value from other perspectives, such as the supply chain perspective. Ganotakis, Hsieh and Love (2012) showed that information systems (IS) adoption in Taiwan enhanced information sharing, not only with supply chain members, but also with external parties. The study also revealed that IS adoption enabled smooth inter-firm communication and information sharing, and assisted in intra-firm information. Lin and Ho 
(2012) investigated the implementation of the collaborative planning, forecasting, and replenishment (CPFR) model for electronic collaboration among supply chain partners in the Taiwanese pharmaceutical and medical industries. Their study produced many CPFR benefits. Accordingly, the CPFR model enhanced medical service quality and avoided inefficient purchases and waste of valuable medical resources. Moreover, the model assisted firms in reducing shipping costs, saving stock space and paper use, promoting service quality, and reducing shortage, urgent order rates, and delivery time.

\section{$\underline{\text { Strategic Business Value }}$}

Strategic business value arises when firms change either their strategy (the way a firm operates) or their products using IT to gain competitive advantages, as well as providing better products and services to customers than their competitors. Oztekin et al. (2013) revealed that innovative product design using mobile technology enabled decision makers to create competitive advantage and improve customer relationships. Bortolotti and Romano (2012) also confirmed the role of IT and automation in lean management specifically in the service industry context in Italy. Their study showed that lean management was a good candidate to apply in service sectors such as the banking industry, where automation and digitalization are essential. Nevertheless, managers need to achieve synergies using ICT to gain competitive advantage and improve customer service. In their conceptual paper, Steger-Jensen et al. (2011) investigated whether using advanced planning and scheduling (APS) was complementary to the enterprise resource planning (ERP) system for supply chain planning and optimization. Their study showed that APS enabled firms to optimize their plans according to their financial and strategic objectives, while solving the capital budgeting problem. Maguire et al. (2012) reported the numerous strategic benefits of ICT adoption for the public sector. These benefits include 
providing better customer care to citizens; reducing bureaucracy; promoting e-government activities and strategic interconnectedness of case departments with other government information systems (IS) (i.e., easy data exchange with other government departments); and improving human resource allocations.

\section{$\underline{\text { Transformational Business Value }}$}

Transformational business value refers to the changes in structure and capacity of a firm as a result of investment in IT, which can add value through better capacity and therefore benefit the firm in the future. A significant body of the relevant literature demonstrates that organizations receive benefits in many forms (e.g., Caniato, Longoni, \& Moretto, 2012; Lewis, Åhlström, Yalabik, \& Mårtensson, 2012; Maguire, et al., 2012; Smith, Ng, \& Maull, 2012). These benefits include enabling firms to simplify the business process by restructuring the internal organizational process and innovatively performing tasks. Lewis et al.'s (2012) case study explored the implementation of the advanced manufacturing technology model in a government-owned TV channel in Sweden. They found that implementing digital TV programs enabled news presenters, editors, and journalists to not only build capability and perform their tasks in a new manner, but also increased the transferability of the technology through mature hardware and software (e.g., all servers run a Silicon Graphics' UNIX variant). The large database, operational effectiveness, and non-proprietary software also enabled schedule visibility for all broadcasts and programs of the new media management system with efficient and effective search capability at reduced connectivity costs.

To understand the electronic procurement (e-procurement) system implementation in various Italian firms, Caniato et al. (2012) showed that e-procurement enabled value-added activities in the purchasing department during the pre-implementation stage. The benefits of 
e-procurement included increased user satisfaction; decision support; spending control and empowerment; supply base rationalization; improved communication and transparency; and increased effectiveness in the entire purchasing process. Furthermore, the adoption of e-procurement enabled employees to manage clerical activities more competently, reduced maverick purchasing and lead times, streamlined the process, and automated non-value-added activities. In addition, companies enjoyed the post-implementation benefits of e-procurement, such as comprehensive spending analysis, higher control and transparency in the transaction process, and more time for strategic and tactical activities in procurement divisions.

Smith et al. (2012) explored the dynamic configuration of resources (i.e., people, technology, organizations, and shared information) that created and delivered value through services between the provider and the customer. They found the following three value propositions and transformations in equipment-based services. The first value proposition is the recovery value proposition cycle, which ensures smooth production by reducing the possibility of minimum disruption when equipment fails. The value cycling is related to material transformation (i.e., the material processing operation). The second value proposition type is the availability value proposition cycle, which ensures the maximum availability of equipment with minimum downtime. This value proposition is related to information transformation. The third value cycle is the outcome value proposition cycle, which ensures better capability for the outcome. This value proposition transformation is related to customer transformation. Accordingly, equipment sellers integrated the customer service system to provide constant advice on the best use of equipment in changing environmental conditions. The transformational benefits of IT adoption are also available for the public sector. Maguire et al. (2012) reported that internal process simplification and better workflow were the results of IT adoption in 
government departments.

Two studies have focused on the co-creation of business value (Holimchayachotikul, Derrouiche, Damand, \& Leksakul, 2013; Maguire, et al., 2012). In an experimental study in France, Holimchayachotikul et al. (2013) introduced the concept of measuring value along the supply chain from a collaborative and balanced scorecard (BSC) perspective in the business-to-business (B2B) context. Their findings suggested that managers heavily utilized graphical analysis results to improve holistic performance. They measured value addition using four BSC perspectives (i.e., business process, partner perspective, financial, and joint innovation and learning). Maguire et al. (2012) reported that science-oriented service thinking facilitated the co-production of service productivity (e.g., between the service purveyor and the stakeholders involved).

\section{Future Research Directions}

Information technology (IT)-enabled business value provides a fascinating opportunity for future research. While the extant literature identifies IT business value as one of the key issues for IT academics and practitioners (Grover \& Kohli, 2012; Kohli \& Grover, 2008; Luftman \& Kempaiah, 2008; Wang, Liang, Zhong, Xue, \& Xiao, 2012), much is still unknown. The paucity of IT business value research in Production Planning \& Control: The Management of Operations, as identified in the previous section, provides the motivation for the papers accepted in this special issue.

Increasingly fickle customer demands, pressures to shorten products lifecycle, and relentless cost pressures combine to place significant demands on the supply chain function. Thus, further research is required to investigate the dynamics of technology-based business networks and innovation ecosystems that can cope with the fast-changing world of the supply chain and 
logistics. Being innovative, by using the internet and the myriad new technologies, such as radio frequency identification devices, hand-held scanners, and software applications, will help, but important questions remain regarding how organizations will deal with the challenges facing innovation ecosystems.

The impact of IT on organizations is visible in the proliferation of the outsourcing boom; cloud technologies; software-as-a-service (SaaS) architectures build on web service technologies; and the demand for seamless interoperability of products and information flows. Further research is required to assess the joint creation or co-creation of business value based on the tight alignment of IT. The prior quantitative studies of IT alignment are largely based on simple bivariate contingency relationships, such as environment/strategy and IT (Coltman, et al., 2011). This type of research ignores the reality that an organization's competitive position is rarely attributed to a single resource or strategic orientation, important as IT may be. Scholars will require a more sophisticated way to accurately conceptualize and measure the true multidimensional nature of IT alignment in a supply chain context.

There is also a tendency among many models of fit to presume that operational managers make resource investment choices on the basis of a rational decision-making process. However, as we know from the marketing and strategy research, this is particularly problematic given the limits of managers and the strong biases that can cause actions to deviate from rationality (Lovallo \& Kahneman, 2003). It is widely accepted that individual managers are cognitively limited and are subject to biases such as over-optimism, recency, exaggeration, and self-preservation. Why is it that the literature on business value and IT alignment does not appear to be constrained in the same way? From a supply chain perspective, the IT alignment literature needs to stop to ask what "type" of alignment is achievable among cognitively constrained 
individuals operating in different parts of the supply chain. The question that arises is: why is it that the IT alignment literature is not constrained by the same biases and risk aversion that characterize behavioral theories of the firm?

The assessment of how business value is shared among a network of participating firms represents a significant and interesting research opportunity. There is a growing realization in supply chain thinking that inventory models are shifting. For example, much attention has previously been given to developing more sophisticated inventory models using technologies based on decision-theoretic logic. More recent approaches have placed emphasis on designing supply chains with virtually no inventory, based on real-time data and rapid replenishment practices. These practices are changing the rules of the game about who controls inventory ordering and releases in a network of participating firms.

Finally, the area of big data analytics (BDA) has emerged as a new frontier for the IT-enabled supply chain in either establishing competitive advantage or exploiting untapped opportunities (Goes, 2014). The ultimate challenge in this domain is to generate business value from the explosion of big data (Beath, Becerra-Fernandez, Ross, \& Short, 2012). The term "value" in the context of big data implies generating economically worthy insights and/or benefits, by analyzing big data through extraction and transformation. Indeed, big data will have added value for business only if it generates a contribution margin, increases profitability, or enhances other non-financial performance (e.g., reduces delivery time or improves customer satisfaction). The extant literature reports that firms will be able to enhance value using big data from the IT-enabled supply chain in the form of financial and non-financial performance. For example, (Schroeck, Shockley, Smart, Romero-Morales, \& Tufano, 2012) found that Automercados Plaza's grocery chain was able to earn a nearly $30 \%$ rise in revenue and a total of 
US\$7 million increase in profitability each year by implementing information integration throughout the organization. (Chandrasekaran, Levin, Patel, \& Roberts, 2013) highlighted that a consumer goods firm was not only able to earn nearly US\$400 million profit, but also improved their delivery timing from $97 \%$ to $99.5 \%$ over three to four years, by developing new algorithms that integrated near-real-time demand data with traditional techniques of forecasting. As shown by (Davenport, 2006), United Parcel Service (UPS) examines usage patterns and complaints data to accurately predict customer defections. Although these studies represent significant potential for BDA, some critical challenges exist with regard to data quality, analytics capability, the capturing of business value, and overall firm performance which can be investigated in future research.

As has been illustrated in this introduction, the three dimensions of business value - transactional, strategic, and transformational — provide a useful framework for assessing the full business benefits of IT. More research is needed particularly in the area of supply chain transformation in which the use value of IT depends on time-consuming investments in organizational change and results in new, often intangible, organizational assets. Research in the application of IT in the supply chain has a bright future and we look forward to forthcoming research on this topic, within the context of production planning and control.

\section{Guide to Papers in the Special Issue}

The papers in this special issue further develop current conceptualizations of IT-based value creation in the supply chain. The papers comprise seven stand-alone research articles.

The first paper, echoing the core theme of this special issue of the effect of IT on supply chain performance, is the article by Yu, titled "The effect of IT-enabled supply chain integration on performance" which extends supply chain research by conceptualizing and examining the 
components and effects of the multidimensional supply chain integration concept.

The second paper titled "The impact of information technology on product recalls: exploring the role of the 6 "Ts" of supply chain management", by Jack Crumbly and Lemuria Carter, presents Roth et al.'s (2008) 6Ts of global recall effectiveness as a useful framework for assessing the role of IT in the recall process.

In the third paper, "An empirical analysis of inter-organizational value co-creation in a supply chain: a process perspective" by Steven Ji-Fan Ren, Cai-hong Hu, E. W. T. Ngai, and Ming-Jian Zhou, the authors seek to identify the process and the mechanism of value co-creation and to realize the relational value. Their research model identifies bilateral idiosyncratic investment and resource inter-dependence as two important steps in the value co-creation process, as well as verifying the effects of value co-creation on partnership quality.

In the fourth paper, "Co-creating value in the automotive supply chain: an RFID application for processing finished vehicles" by Stefanie Herrmann, Helen Rogers, Marina Gebhard, and Evi Hartmann, the authors provide insights into a radio frequency identification (RFID) application and the subsequent distribution process of vehicles at a German car manufacturer. The paper illustrates how the exchange of real-time data in the distribution process leads to better capacity management at various stages along the supply chain and how RFID improves the process through enhanced visibility.

In the fifth paper, "Impact of information integration on decision making in a supply chain network" by Adarsh Kumar Singh and Ashish Garg, the authors address the influence of integrating information along supply chain networks in the supplier selection decision-making problem. The paper analyzes the impact of integrating information for stable and random orders on fulfilling the strategic objectives of the organization. 
In the sixth paper, "A multi-mode critical chain scheduling method based on priority rules" by Wuliang Peng, Min Huang, and Hao Yongping, the authors evaluate the performances of priority rules for the critical chain project scheduling problem with multiple execution modes. Firstly, a multi-mode critical chain project scheduling problem (MCCPSP) is formulated in which the following factors are all considered: precedent relationships, resource constraints, multiple modes, and the characteristics of the critical chain method. Subsequently, the heuristic solution of the MCCPSP is designed, and the priority rules used in resource-constrained project scheduling problems (RCPSPs) are built into the heuristic of the MCCPSP. Finally, a large number of existing priority rules are evaluated on the Project Scheduling Problem Library (PSPLIB) datasets by computation experiments.

In the seventh paper, "Factors affecting selection decision of auto-identification technology in warehouse management: an international Delphi study", by Hassan Mayadah, Ali Maged, Aktas Emel, and Alkayid Kholoud, the authors discuss the selection process of an example of automatic identification technology: radio frequency identification (RFID). The authors have synthesized the literature and identified the set of factors that affects the technology selection decision. Based on these factors, the authors have developed a multi-stage selection framework for auto-ID technology.

\section{Acknowledgements}

This special issue is the result of an intensive evolution of various stakeholders, including the guest editors and the journal editorial board. Firstly, we would like to thank Dr Stephen J. Childe for his comments and guidelines on the early version of the call for papers proposal that greatly helped improve the proposal. We would like to acknowledge his support and guidance during the whole review cycle of this special issue. Also, special thanks go to Heather Childe, the assistant 
to the editor, for her 24/7 support during this amazing experience. We would also like to acknowledge the great work done by the team of reviewers who devoted their time to providing valuable comments to improve those manuscripts that were accepted for this special issue. Finally, we would like to thank all the authors of the papers included in this special issue.

This research was partially funded by grants from the Australian Research Council (LP 120100422).

\section{Guest Editors}

Samuel Fosso Wamba

Shahriar Akter

Tim Coltman

Eric W. T. Ngai 


\section{References:}

Barney, J. (1991). Firm Resources and Sustained Competitive Advantage. Journal of Management, 17(1), 99-120. doi: 10.1177/014920639101700108

Beath, C., Becerra-Fernandez, I., Ross, J., \& Short, J. (2012). Finding Value in the Information Explosion. MIT Sloan Management Review, 53(4), 18-20.

Bortolotti, T., \& Romano, P. (2012). 'Lean first, then automate': a framework for process improvement in pure service companies. A case study. Production Planning \& Control, 23(7), 513-522. doi: $10.1080 / 09537287.2011 .640040$

Bowman, C., \& Ambrosini, V. (2000). Value Creation Versus Value Capture: Towards a Coherent Definition of Value in Strategy. British Journal of Management, 11(1), 1-15. doi: 10.1111/1467-8551.00147

Caniato, F., Longoni, A., \& Moretto, A. (2012). Effective eProcurement implementation process. Production Planning \& Control, 23(12), 935-949.

Carr, N. G. (2003). IT Doesn't Matter. Harvard Business Review, 81(5), 41-49.

Carson, S. J., Timothy, M. D., Grahame, R. D., \& George, J. (1999). Understanding Institutional Designs Within Marketing Value Systems Journal of Marketing 63, 115-130.

Cederlund, J. S., Kohli, R., Sherer, S. A., \& Yao, Y. (2007). How Motorola Put CPFR into Action Supply Chain Management Review, 11(7), 28-35.

Chandrasekaran, S., Levin, R., Patel, H., \& Roberts, R. (2013). Winning with IT in consumer packaged goods: Seven trends transforming the role of the $\mathrm{ClO}$ (pp. 1-8): McKinsey \& Company.

Coltman, T., \& Devinney, T. M. (2013). Modeling the Operational Capabilities for Customized and Commoditized Services. Journal of Operations Management 31(7/8), 555-566.

Coltman, T., Devinney, T. M., \& Midgley, D. F. (2011). Customer Relationship Management and Firm Performance. Journal of Information Technology, 25(3), 205-219.

Davenport, T. H. (2006). Competing on analytics. harvard business review, 84(1), 98-107.

Fosso Wamba, S. (2012). RFID-Enabled Healthcare Applications, Issues and Benefits: An Archival Analysis (1997-2011). Journal of Medical Systems, 1-6.

Frohlich, M. T., \& Westbrook, R. (2002). Demand chain management in manufacturing and services: web-based integration, drivers and performance. Journal of Operations Management, 20(6), 729-745. doi: 10.1016/s0272-6963(02)00037-2

Gable, G. (2010). Strategic information systems research: An archival analysis. The Journal of Strategic Information Systems, 19(1), 3-16. doi: http://dx.doi.org/10.1016/i.jsis.2010.02.003

Ganotakis, P., Hsieh, W.-L., \& Love, J. H. (2012). Information systems, inter-functional collaboration and innovation in Taiwanese high-tech manufacturing firms. Production Planning \& Control, 24(8-9), 837-850. doi: 10.1080/09537287.2012.666876

Goes, P. B. (2014). Big Data and IS Research. [Article]. MIS Quarterly, 38(3), iii-viii.

Gregor, S., Martin, M., Fernandez, W., Stern, S., \& Vitale, M. (2006). The transformational dimension in the realization of business value from information technology. The Journal of Strategic Information Systems, 15(3), 249-270. doi: http://dx.doi.org/10.1016/i.jsis.2006.04.001

Grover, V., \& Kohli, R. (2012). Cocreating IT value: new capabilities and metrics for multifirm environments. MIS Q., 36(1), 225-232.

Guy, G. (2010). Strategic information systems research: An archival analysis. The Journal of Strategic Information Systems, 19(1), 3-16. doi: 10.1016/j.jsis.2010.02.003

Holimchayachotikul, P., Derrouiche, R., Damand, D., \& Leksakul, K. (2013). Value creation through collaborative supply chain: holistic performance enhancement road map. Production Planning \& Control, 25(11), 912-922. doi: 10.1080/09537287.2013.780313

Jap, S. D., \& Anderson, E. (2003). Safeguarding Interorganizational Performance and Continuity under Ex 
Post Opportunism. Management Science, 49(12), 1684-1701. doi: 10.2307/4133978

Kohli, R., \& Grover, V. (2008). Business value of IT: an essay on expanding research directions to keep up with the times. Journal of the association for information systems, 9(1), 1.

Lepak, D. P., Smith, K. G., \& Taylor, M. S. (2007). Value Creation and Value Capture: A Multilevel Perspective. Academy of Management Review, 32(1), 180-194. doi: 10.5465/amr.2007.23464011

Lewis, M., Åhlström, P., Yalabik, B., \& Mårtensson, P. (2012). Implementing advanced service technology in the public sector: an exploratory study of the relevance and limitations of insights from private sector manufacturing technology implementation. Production Planning \& Control, 24(10-11), 916-930. doi: 10.1080/09537287.2012.666901

Lin, R.-H., \& Ho, P.-Y. (2012). The study of CPFR implementation model in medical SCM of Taiwan. Production Planning \& Control, 25(3), 260-271. doi: 10.1080/09537287.2012.673646

Lovallo, D., \& Kahneman, D. (2003). Delusions of success. How optimism undermines executives' decisions. Harvard Business Review, 81(7), 56-63.

Luftman, J., \& Kempaiah, R. (2008). Key issues for IT executives 2007. MIS Quarterly Executive, 7(2), 99-112.

Lusch, R. F., Vargo, S. L., \& O’Brien, M. (2007). Competing through service: Insights from service-dominant logic. Journal of Retailing, 83(1), 5-18. doi: http://dx.doi.org/10.1016/j.jretai.2006.10.002

Maguire, S., Ojiako, U., Papadopoulos, T., Shafti, F., Koh, L., \& Kanellis, P. (2012). Synchronicity and alignment of productivity: the real value from Service Science? Production Planning \& Control, 23(7), 498-512. doi: 10.1080/09537287.2011.640038

Melville, N., Kraemer, K., \& Gurbaxani, V. (2004). INFORMATION TECHNOLOGY AND ORGANIZATIONAL PERFORMANCE: AN INTEGRATIVE MODEL OF IT BUSINESS VALUE. [Article]. MIS Quarterly, 28(2), 283-322.

Mirani, R., \& Lederer, A. L. (1998). An instrument for assessing the organizational benefits of IS projects. Decision Sciences, 29(4), 803-838.

Nagayama, K., \& Weill, P. (2004). Seven Eleven Japan: Reinventing the Retail Business Model CISR Working Paper (Vol. 338, pp. 1-20): MIT.

Ngai, E. W. T., \& Wat, F. K. T. (2002). A literature review and classification of electronic commerce research. Information \& Management, 39(5), 415-429.

Oztekin, A., Iseri, A., Zaim, S., \& Nikov, A. (2013). A Taguchi-based Kansei engineering study of mobile phones at product design stage. Production Planning \& Control, 24(6), 465-474. doi: 10.1080/09537287.2011.633575

Palmer, J. W., \& Markus, M. L. (2000). The Performance Impacts of Quick Response and Strategic Alignment in Specialty Retailing. Information Systems Research, 11(3), 241-259. doi: 10.1287/isre.11.3.241.12203

Pitelis, C. N. (2009). The Co-Evolution of Organizational Value Capture, Value Creation and Sustainable Advantage. Organization Studies, 30(10), 1115-1139. doi: 10.1177/0170840609346977

Plugge, A., \& Bouwman, H. (2012). Fit between sourcing capabilities and organisational structure on IT outsourcing performance. Production Planning \& Control, 24(4-5), 375-387. doi: 10.1080/09537287.2011.648489

Roth, A. V., Tsay, A. A., Pullman, M. E., \& Gray, J. V. (2008). UNRAVELING THE FOOD SUPPLY CHAIN: STRATEGIC INSIGHTS FROM CHINA AND THE 2007 RECALLS*. Journal of Supply Chain Management, 44(1), 22-39. doi: 10.1111/j.1745-493X.2008.00043.x

Santa, R., Hyland, P., \& Ferrer, M. (2013). Technological innovation and operational effectiveness: their role in achieving performance improvements. Production Planning \& Control, 25(12), 969-979. doi: 10.1080/09537287.2013.785613 
Schroeck, M., Shockley, R., Smart, J., Romero-Morales, D., \& Tufano, P. P. (2012). Analytics: The real-world use of big data. NY, USA: IBM Institute for Business Value.

Smith, L., Ng, I., \& Maull, R. (2012). The three value proposition cycles of equipment-based service. Production Planning \& Control, 23(7), 553-570. doi: 10.1080/09537287.2011.640055

Steger-Jensen, K., Hvolby, H.-H., Nielsen, P., \& Nielsen, I. (2011). Advanced planning and scheduling technology. Production Planning \& Control, 22(8), 800-808. doi: 10.1080/09537287.2010.543563

Vargo, S., \& Lusch, R. (2008). Service-dominant logic: continuing the evolution. Journal of the Academy of Marketing Science, 36(1), 1-10. doi: 10.1007/s11747-007-0069-6

Wang, N., Liang, H., Zhong, W., Xue, Y., \& Xiao, J. (2012). Resource Structuring or Capability Building? An Empirical Study of the Business Value of Information Technology. [Article]. Journal of Management Information Systems, 29(2), 325-367.

Williamson, O. E. (1985). The Economic Institutions of Capitalism: Firms, Markets and Relational contracting New York: The Free Press, a Division of Macmillan, Inc. 


\section{Appendix A}

The methodology followed a similar approach to that used by (Ngai \& Wat, 2002) and Gable (2010). This methodology consisted of the following: (i) developing a classification framework; (ii) conducting a review of papers in the journal, Production Planning \& Control: The Management of Operations, that dealt with the business value of IT using the descriptors "IT" or "information technology," "e-business" or "electronic business," and "BV" or "business value"; and (iii) classifying all identified articles. Our study's scope was limited to one journal and focused only on articles published between 2009 and 2014.

\section{Review techniques, scope of the review, time length, and justifications}

The process helped to identify articles in the selected journal that dealt with issues related to the business value of IT. Articles regarding the business value of IT were emphasized. Such articles addressed various themes, including transactional, strategic, and transformational IT values. Initially, a trained research assistant was employed to use keywords in the search. As stated above, these keywords were "IT" or "information technology," "e-business" or "electronic business," and "BV" or "business value." In the first phase, the obtained articles were slightly relevant, or not relevant, to the actual requirement of the study topic (i.e., the business value of IT). Each published article was consulted manually. Consequently, 13 complete articles with their references as published in the journal were downloaded. The references were managed through EndNote. The relevance of the downloaded articles was then checked by a co-author from the research team. One article was not considered further because the key researchers deemed that it was irrelevant to the scope of the current review.

The relevance of the articles was evaluated based on whether the themes could be linked to the business value of IT and on whether specific applications were relevant to the three types of 
IT business value added to firms, in general, and any departments or units, in particular. This criterion was introduced to narrow down the scope of the search, thus avoiding potential duplications. Consequently, the study considered 12 relevant articles published between January 2009 and June 2014. Articles published from 2009 onwards were selected as this year marked the beginning of increasing attention toward the changes in firms' traditional value creation process and the adoption of IT-based value creation. Articles published in 2014 were selected because the most recent studies likely to be addressed within this review were reported in this year.

This journal was specifically selected because it publishes academic articles in diverse management streams, including operation and production management, performance measurement, and management capping the flavor of information technology, and has played an authoritative role over the past decades.

The review methodology used in this study is consistent with that in the literature (Fosso Wamba, 2012; Guy, 2010). For instance, (Guy, 2010) reported on a review of articles published in The Journal of Strategic Information Systems up to 2009, while (Fosso Wamba, 2012) conducted a comprehensive review of the articles on RFID technology that were published between 1997 and 2011 in the Journal of Medical Systems. In addition to the classification of articles in terms of dimensions and settings, research methods were identified (Table 1). Consistent with the research approach followed by previous studies (e.g.,Melville, Kraemer, \& Gurbaxani, 2004), we excluded book reviews, conference papers, working papers, unpublished theses, brief editorials, and commentaries: only papers published in English were considered.

Considering the scope of the current review, we classified topics into three broader categories as follows: (a) transactional business value of IT; (b) strategic business value of IT; and (c) transformational business value creation of IT within firms. For the transactional business 
value of IT, the review covers only studies that investigated and determined the transactional types of value creation (e.g., reduction of operational costs, improvement of workforce productivity, and improvement of financial returns) as a consequence of IT/IS adoption. The second category refers to articles in the journal which have identified the strategic benefits that have driven firms to use IT. Such benefits can create competitive advantages, provide better customer service than competitors, and align the firm's IT strategy with its business strategy. The third category (i.e., transformational benefits of IT) was motivated by a better understanding of the development of IT research as evidenced in the literature beyond the first two categories: these types of IT benefits have recently been developed in the literature (Gregor, et al., 2006). Research on the transformational benefits of IT studies (if any) provides a clear illustration of why the use of IT either facilitates or impedes business value in any specific firm setting.

The review identified twelve relevant articles published between January 2009 and June 2014. The articles were classified according to three types of IT business value (i.e., transactional, strategic, and transformational); research methods (e.g., mathematical/analytic, survey, archival, experimentation, case/field study, and literature review, among others); and their settings (public sector, services, manufacturing, and others). 


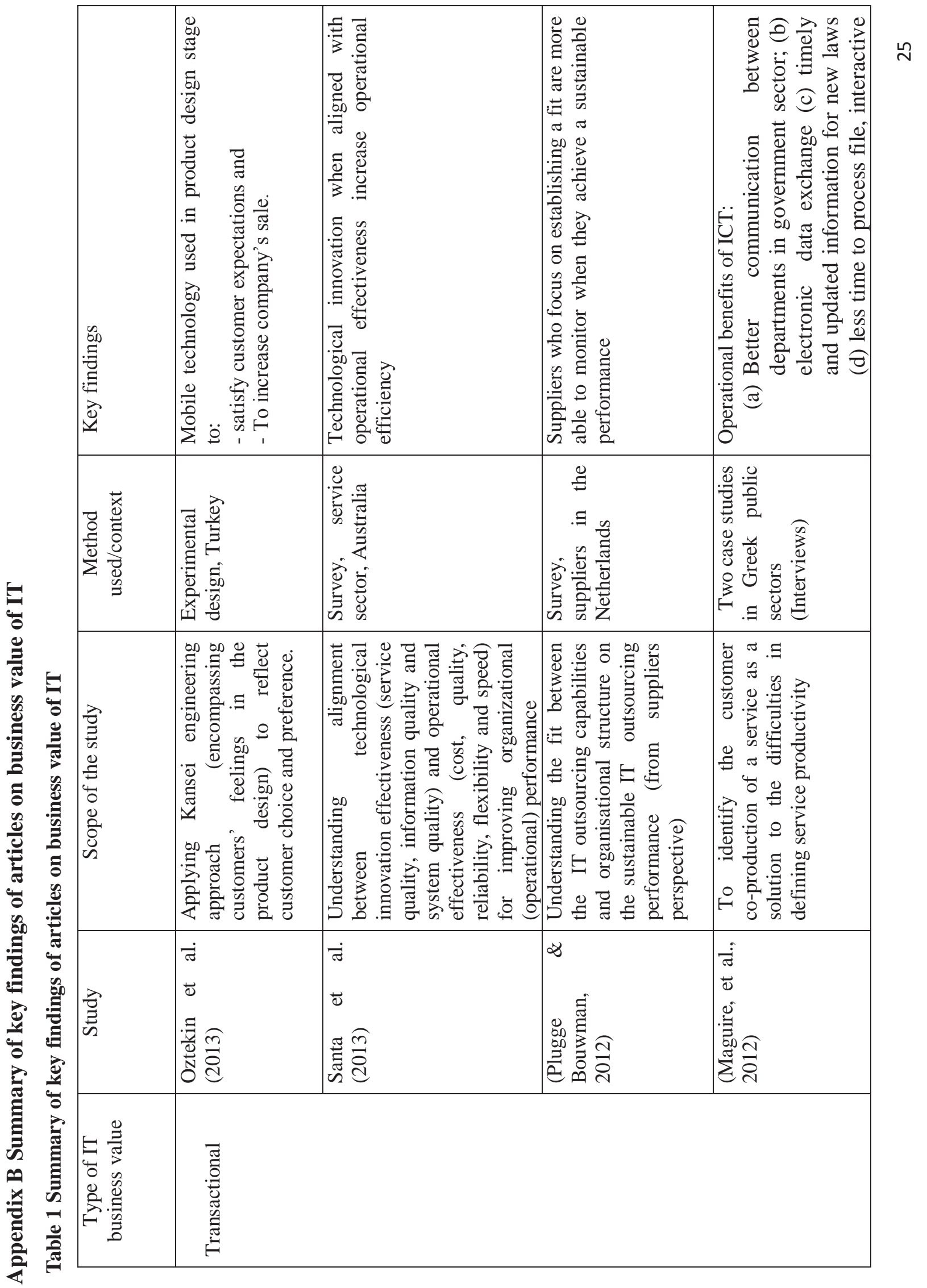




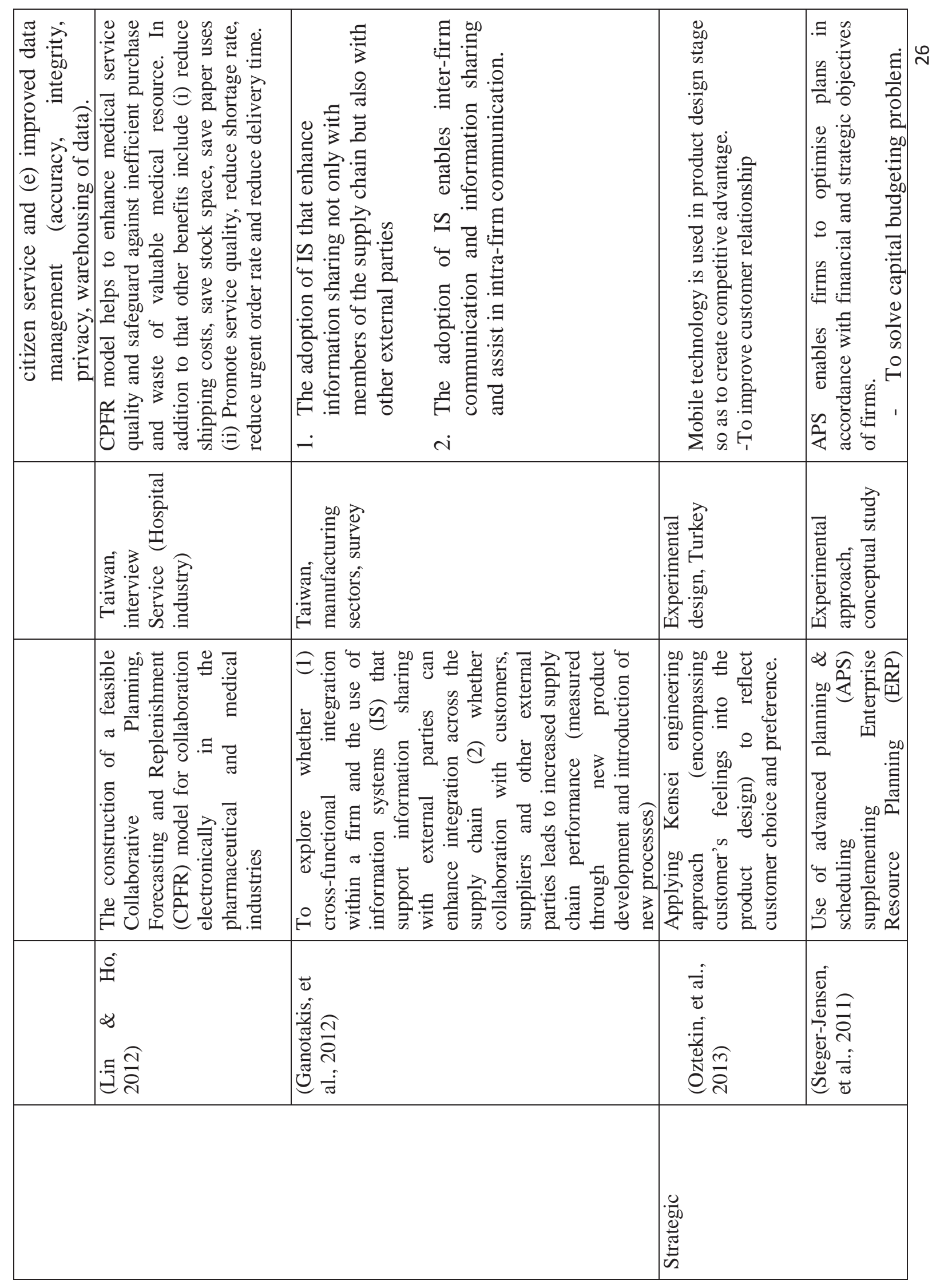




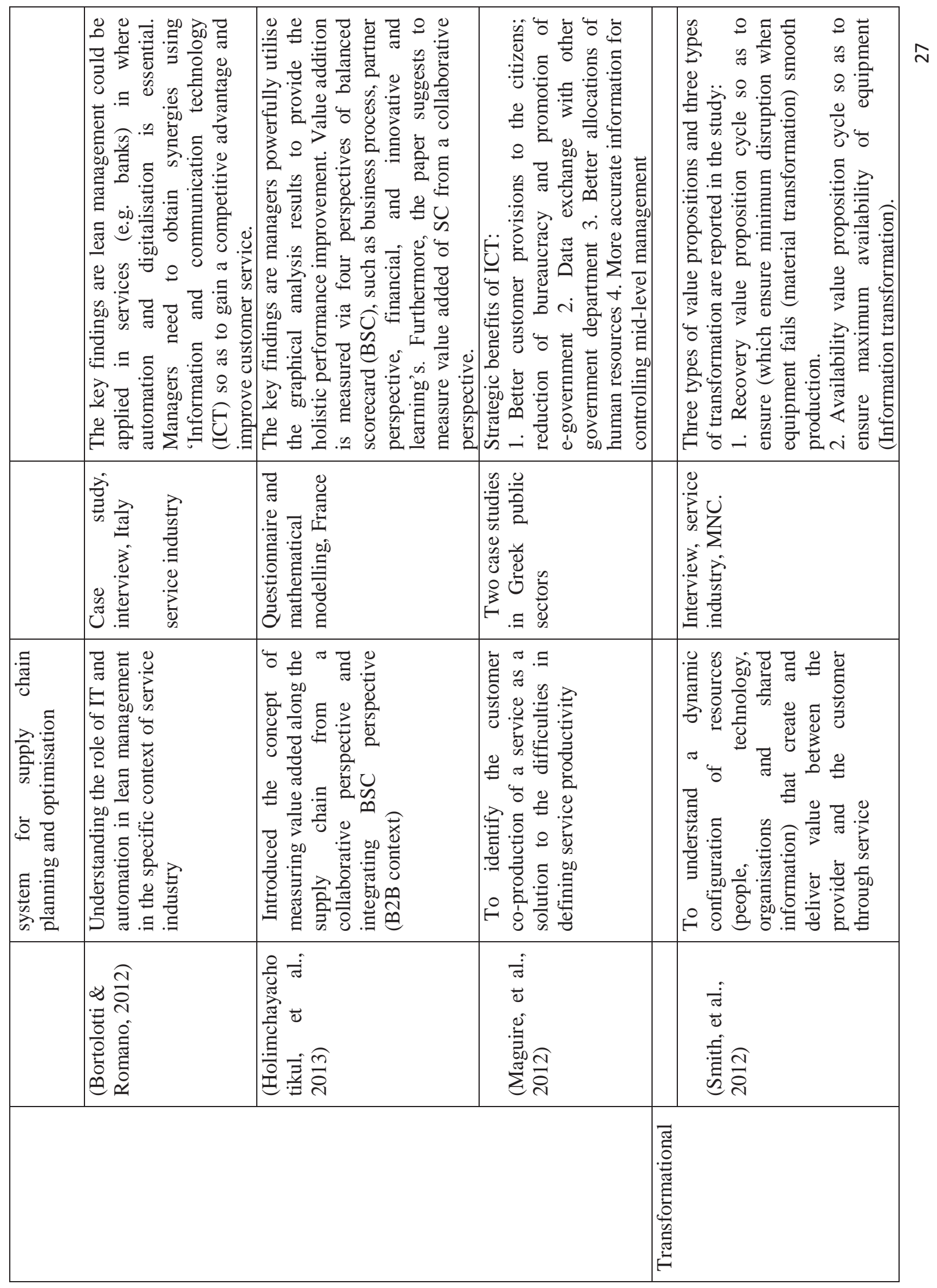




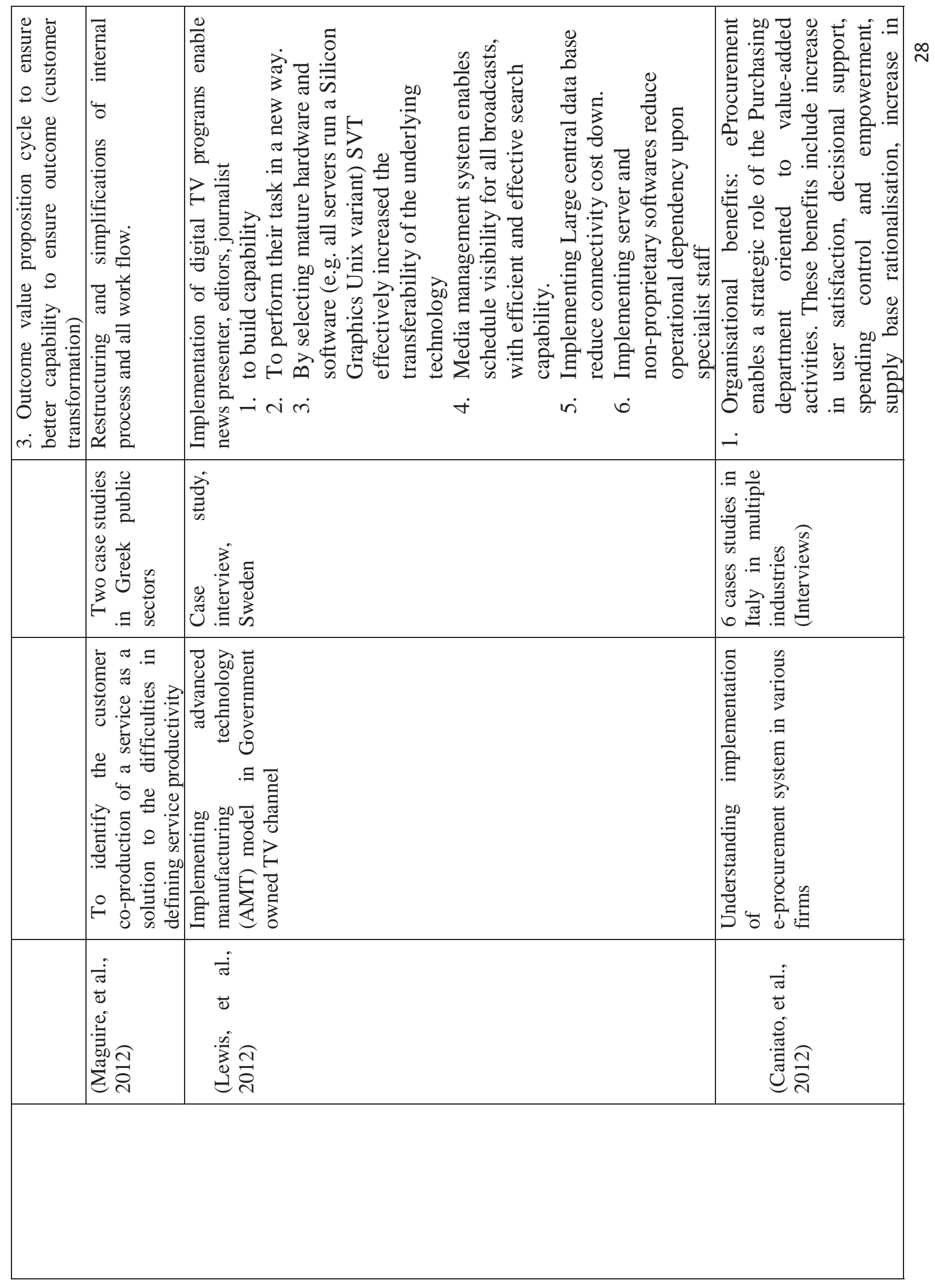




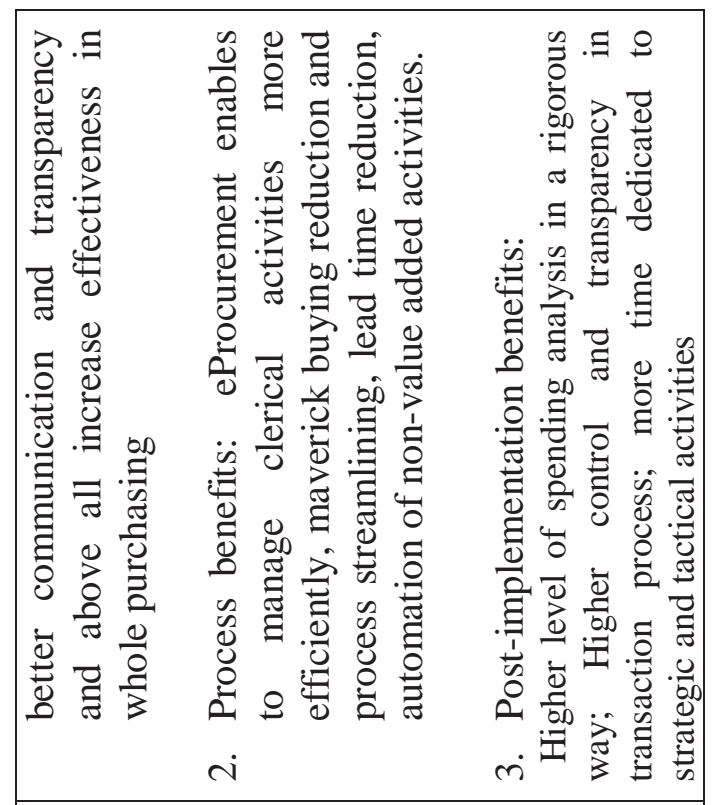

